\title{
Electrospray Printing of Graphene Layers for Chemiresistive Gas Sensors ${ }^{\dagger}$
}

\author{
Sergio Masa ${ }^{1}$, María José Mena ${ }^{2}$, Esther Hontañón ${ }^{1, *}$, Jesús Lozano ${ }^{3}$, Siamak Eqtesadi ${ }^{4}$ and \\ Adolfo Narros ${ }^{2}$ \\ 1 Department of Sensors and Ultrasonic Systems, Spanish National Research Council, C/Serrano 144, \\ 28006 Madrid, Spain; esther.hontanon@csic.es \\ 2 Department of Chemical Industrial and Environmental Engineering, Polytechnic University of Madrid, \\ C/José Gutiérrez Abascal 2, 28006, Madrid, Spain; mj.mena@alumnos.upm.es (M.J.M.); \\ email2@gmail.com (A.N.) \\ 3 Department of Electrical, Electronic and Automatic Engineering, University of Extremadura, Av. de Elvas \\ s/n, 06006 Badajoz, Spain; jesuslozano@unex.es \\ 4 Abalonyx AS, Forskningsveien 1, 0373 Oslo, Norway; se@abalonyx.no \\ * Correspondence: esther.hontanon@csic.es; Tel.: +34-91-5618806 \\ † Presented at the 7th International Electronic Conference on Sensors and Applications, 15-30 November \\ 2020; Available online: https://ecsa-7.sciforum.net/.
}

Published: 15 November 2020

\begin{abstract}
In this work we investigate the electrospray technique for the preparation of graphene layers for use in chemiresistive gas sensors. A dispersion of reduced graphene oxide (rGO) in isopropanol $(0.1 \mathrm{mg} / \mathrm{mL})$ is electrosprayed and the $\mathrm{rGO}$ flakes are deposited onto a polymeric substrate with printed interdigitated electrodes. The surface area of the substrate covered with rGO is mainly determined by the distance between the needle and the substrate, while the rGO deposition pattern strongly depends on the flowrate and the applied voltage. Homogeneous layers of rGO are obtained in stable cone-jet regime, and the room temperature detection behavior of the sensors towards $\mathrm{NO}_{2}, \mathrm{O}_{3}$ and $\mathrm{CO}$ is assessed. The sensors were not capable of detecting $\mathrm{CO}$ (up to 5 ppm), but they detected $0.2 \mathrm{ppm} \mathrm{NO}_{2}$ and $0.05 \mathrm{ppm} \mathrm{O}_{3}$. The results are encouraging regarding the use of electrospray for production of low-cost and low-power consumption gas sensors based on graphene for air quality applications.
\end{abstract}

Keywords: reduced graphene oxide; electrospray; deposition pattern; chemiresistive sensor; air pollutants

\section{Introduction}

Chemiresistor is the most widely used configuration of gas sensors. In chemiresistive sensors, gases are detected by measuring the changes in the electrical resistance of sensing layers induced by the adsorption of the gas molecules. In commercial chemiresistive sensors the sensing layer is a thick or thin film of a metal oxide semiconductor (MOS) deposited onto a silicon or ceramic substrate with metallic electrodes and a resistor micromachined on its surface. The later allows heating the sensing layer to a high temperature dependent on the nature of the gas to be detected, in general above 300 ${ }^{\circ} \mathrm{C}$. MOS gas sensors are produced by means of cost intensive technologies used in microelectronics and surface coating industries (e.g., silicon micro-machining, sputtering, laser ablation or chemical vapor deposition), which commonly involve multistep, slow, and complex processes (e.g., lithography and etching) under extreme conditions (e.g., high vacuum and high temperature) [1]. Also, the power consumption of MOS gas sensors is high, typically tens of $\mathrm{mW}$, due to the high working temperatures. The rapidly growing demand of miniaturized, low-cost, and low-power 
consumption sensors for use in portable and wearable devices and systems for a broad spectrum of applications (e.g., air quality monitoring in smart cities) is driving the development of novel materials showing outstanding gas sensing performance at ambient temperature such as nanostructured MOS, conductive polymers and carbon-based materials, which can be supported on affordable substrate materials like plastic, paper or fabrics [2-4].

Graphene comprises a family of materials, namely pristine graphene (PG), graphene oxide (GO) and reduced graphene oxide (rGO) which are being intensively investigated for trace gas/vapor sensing at room temperature because of its high surface-to-volume ratio, specific surface area, charge carrier mobility, and chemical activity at defect sites; as well as for its unique band structure and tunable defect density [5-10]. Pure defect-free PG possesses high electrical conductivity and low intrinsic noise, but is very inert due to the absence of hanging bonds on its surface and edges, as required for gas adsorption, and needs to be functionalized with polymers, metals or other modifiers. In addition, the methods currently used for the production of PG are costly and hazardous, not suitable for mass production and do not allow a good control of the final product. A cost-effective method to produce graphene in large quantities is to firstly produce GO by the oxidative exfoliation of graphite in liquid phase and to subsequently reduce it by chemical or thermal means to obtain rGO. The low conductivity of GO, dependent upon the degree of oxidation, is a clear disadvantage, whereas the abundance of oxygen rich functional groups on its surface makes GO very reactive and, hence, a potentially promising candidate for gas sensing. Finally, rGO has proved advantages over PG considering the low production costs, fine-tuning of structure and properties such as electrical conductivity, dispersal in water, and the ease of surface modification and functionalization [11-16]. A drawback of graphene materials containing oxygen groups is that these strongly interact with reactive adsorbates, acting as higher-energy binding sites and limiting reversibility and repetitive use of graphene-based gas sensors. This limitation can be overcome by means of UV irradiation. It has been proved that UV light accelerates gas desorption from nanostructured MOS, graphene and other emerging 2D materials suitable for gas sensing at room temperature, and can also enhance sensor sensitivity and selectivity to specific gases [17-20].

Printing technologies are promising routes for the production of micro/nano-devices because they allow processing diverse electronic materials compatible with flexible/bendable substrates without involving extreme conditions, complex processes and/or costly equipment [21-23]. Inkjet printing (IJP) is the most commonly used method for research and development of functional material-based devices due to the ease of prototyping, large surface area coverage, and scalability for mass production. The inkjet print-head uses a short pressure pulse generated either thermally or piezoelectrically to expel one or more liquid droplets $(\sim 100 \mathrm{pL})$ of a colloidal suspension out of a micrometers-sized nozzle $(30-60 \mu \mathrm{m})$. IJP allows producing versatile micro/nano-films with no need of masks, stencils or templates; on-demand digital printing in areas only where the material needs to be deposited; and multiple layers with well-controlled material deposition and good precision. The major limitation of IJP is the narrow value range that ink properties (e.g., viscosity, surface tension, particle size, and particle concentration) must fall within for consistent droplet formation and pattern printing. The creation of a homogeneous film with constant thickness using IJP is a challenge due to the tolerance of the nominal droplet volume and the accumulation of material at the edge of the printed structure due to the evaporation gradient, so called "coffee ring" effect. The IJP resolution is also typically limited to micrometers, since thermal and piezoelectric actuators are unable to dispense droplets smaller than the droplet size. Finally, IJP is one of the slowest printing techniques due to the requirement of the print-head to scan the substrate. The printing speed can be increased by employing a greater number of nozzles, reducing the amount of movement required to build the pattern, potentially reaching speeds of $10 \mathrm{~m} / \mathrm{min}$. IJP has been successfully applied to the deposition of thin films of graphene and graphene-metal, -metal oxide, and -polymer nanocomposites onto rigid and flexible substrates for use in chemiresistive gas sensors [24-29].

Electrospray (ES) has gained interest for production of low-cost micro/nano-devices because of its capability to create thin films of high quality with more precise control of the film properties compared to other printing techniques [30-32]. In an ES system, a liquid with sufficient electrical 
conductivity is fed at a constant rate $(0.5-50 \mu \mathrm{L} / \mathrm{min})$ through a capillary tube (30-300 $\mu \mathrm{m})$ that is charged at high potential relative to a nearby ground electrode. On the tip of the capillary tube the liquid meniscus takes a conical shape with a fine jet issuing from the cone apex. Varicose waves on the surface of the jet lead to jet break-up into small highly charged droplets which due to Coulomb repulsion are radially dispersed. Clogging is generally not an issue for ES even with suspensions of high particle concentration because the bore is typically two orders of magnitude larger than the jet/droplet diameter. Another key feature of ES is the quasi monodispersity of the droplets. The capability of producing monodisperse droplets with relative ease is unmatched by any other droplet generation scheme, especially in the submicron range. ES is capable of achieving extremely high resolution, down to $1 \mu \mathrm{m}$, overcoming the resolution limitation of IJP. To achieve this, however, a much smaller nozzle is required, and the construction of micrometer and sub-micrometer-sized metal-coated nozzles with a high consistency involves a certain complexity and intricacy. In addition, very dilute inks need to be used to avoid nozzle clogging. The major ES drawback is the low flow rate at which the cone-jet can be established. This drawback has been addressed through multiplex ES (MES) techniques, demonstrating the simultaneous operation of hundreds of ES sources and a remarkable packing density exceeding $10^{4}$ sources $/ \mathrm{cm}^{2}$ [33]. Thin films of MOS and conductive polymers have been prepared by ES of precursor solutions or nanoparticle suspensions for gas sensing applications [34-39]. Only recently ES has received attention for the preparation of gas sensors based on graphene $[40,41]$.

In this work, we explore the feasibility of electrospray for the preparation of graphene films for gas sensing. For that purpose, we choose commercial graphene (rGO) and characterize the deposits of electrosprayed rGO in terms of surface coverage area and deposition pattern in dependence of the main electrospray parameters, these are the needle-substrate distance, flowrate and applied voltage. Moreover, we characterize the performance of the electrosprayed rGO films for detecting $\mathrm{NO}_{2}, \mathrm{O}_{3}$ and $\mathrm{CO}$ in levels relevant to air quality applications.

\section{Materials and Methods}

\subsection{Reduced Graphene Oxide}

We use rGO podwer (E800, Abalonyx AS, Norway) produced by a modified Hummer's method followed by thermal reduction of $\mathrm{GO}$ at $800{ }^{\circ} \mathrm{C}$. The manufacturer provided the values of the specific surface area $\left(436 \mathrm{~m}^{2} / \mathrm{g}\right)$, electrical conductivity $(20 \mathrm{~S} / \mathrm{m})$ and carbon-to-oxyxgen atomic ratio (35) of the rGO. Raman spectroscopy was used to analyze the quality of the rGO. The Ramam spectrum of monolayer defect-free graphene exhibits a relatively simple structure with two bands, $G$ and 2D, with peak intensities at $\lambda \sim 1587,2679 \mathrm{~cm}^{-1}$; the peak intensity ratio $\mathrm{IG}_{\mathrm{G}} / \mathrm{I}_{2 \mathrm{D}}$ is 0.5 ; and the $2 \mathrm{D}$ band is a single symmetric peak with a full width at half maximum (FWHM) $30 \mathrm{~cm}^{-1}$ [42]. As can be seen in Figure $1 \mathrm{a}$, the Ramam spectrum of the rGO used here deviates from that previously described. Both $\mathrm{G}$ and 2D bands are shifted towards higher wavelength numbers $\left(\lambda \sim 1637,3448 \mathrm{~cm}^{-1}\right)$, which is mainly attributed to the effect of the substrate supporting the rGO sample. Also, the peak intensity ratio is lower ( $\left.\mathrm{I}_{\mathrm{G}} / \mathrm{I}_{2 \mathrm{D}} \sim 0.3\right)$, and the $2 \mathrm{D}$ band is not fully symmetric and much broader (FWHM $170 \mathrm{~cm}^{-1}$ ) than for monolayer graphene. These results reveal that the rGO is multilayer graphene $[42,43]$. The peak observed at $\lambda \sim 1383 \mathrm{~cm}^{-1}$ corresponds to the D band of graphene, which is a measure of the level of disorder or defects in the material. The low intensity of the $D$ band with respect to the $G$ band indicates that the rGO is highly ordered [44]. X-ray difraction (XRD) examined the crystallinity of the rGO. In Figure $1 b$, the peak at $2 \theta \sim 26.52^{\circ}$ matches the position of the crystal phase (002) for graphite, but the broader peak for rGO implies that the phase (002) is arranged randomly as compared to the high crystallization structure of graphite. The poor arrangement may be due to the formation of single or a few layers of rGO after reduction from GO. The interlayer spacing given by Bragg's law is 0.3373 $\mathrm{nm}$, and the thickness of the rGO calculated by using Scherrer's equation and the FWHM of the (002) peak reaches $2.33 \mathrm{~nm}$. Thus, the average number of layers in the stacked multilayer rGO is 7 . These results are consistent with those reported by other authors for rGO produced by the same method $[45,46]$. Finally, Fourier transform infra-red spectroscopy (FTIR) provided information about the 
funcional groups in the rGO. Figure 1c evidences the presence in the rGO of bond hydroxyl groups $-\mathrm{OH}\left(\lambda \sim 1380,3460 \mathrm{~cm}^{-1}\right)$, epoxy groups C-O-C $\left(\lambda \sim 1000,1130 \mathrm{~cm}^{-1}\right)$, and to a lesser extent also carboxyl groups - $\mathrm{COOH}\left(\lambda \sim 1740 \mathrm{~cm}^{-1}\right)$ [43-45].

(a)

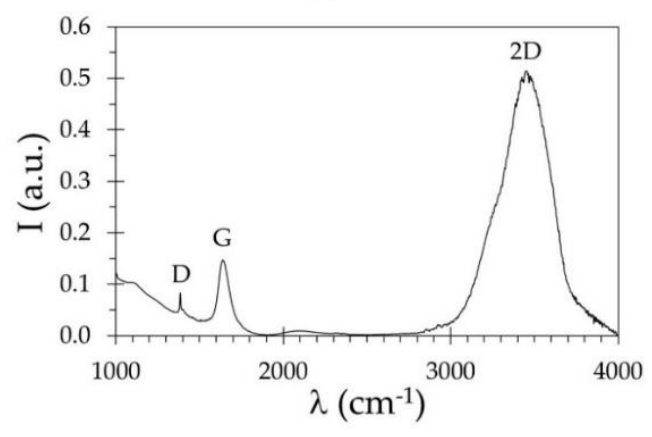

(b)

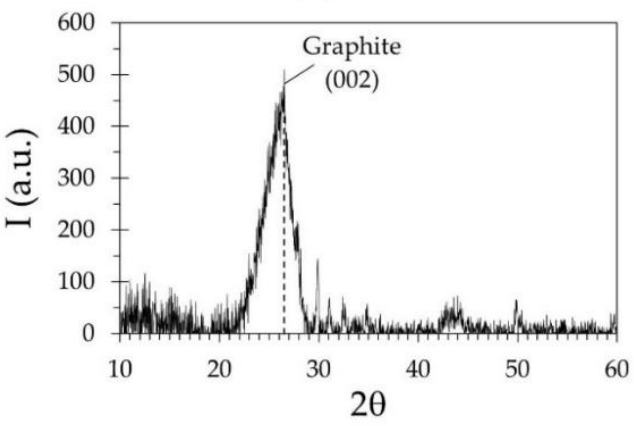

(c)

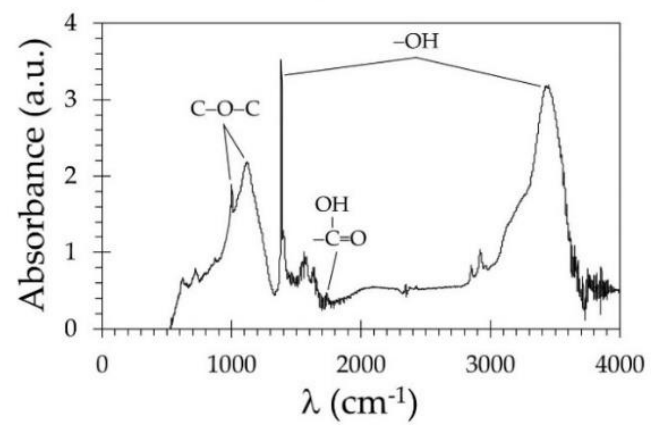

Figure 1. (a) XRD diffractogram, (b) Raman spectrum, and (c) FTIR spectrum of rGO powder.

\subsection{Sensor Preparation}

Sensors are prepared by electrospray of a liquid suspension of rGO and subsequent deposition of the rGO flakes from the gas phase onto a substrate. The electrospray system and the substrate are depicted in Figure 2. The electrospray setup is arranged horizontally and its main components are a syringe pump (SyringePump ${ }^{\circledR}$ NE-1000) and a high voltage supply (Ioner ${ }^{\circledR}$ HV-7020). The rGO suspension is delivered through a stainless steel needle (Neolus ${ }^{\circledR}$ NN-2525R) with a straight cylindrical tip of $300 \mu \mathrm{m}$ in inner diameter, and a CMOS camera (The Imaging Source ${ }^{\circledR}$ DMK 23UP1300) allows visualizing and recording the liquid that comes out from the needle tip. The substrate (Eurocuircuits NV, Belgium) is a circular plate of a diameter of $15.24 \mathrm{~mm}$ and a thickness of $1.55 \mathrm{~mm}$. The base material is a polymer (FR4IMP) commonly used in printed circuit boards (PCBs) with 4 interdigitated electrodes (IDEs) of copper on its upper surface. The interdigital gap length is $0.1 \mathrm{~mm}$ and the surface area of the IDEs is $7.3 \mathrm{~mm}^{2}$. The latter is the active area that is coated with the sensing material.

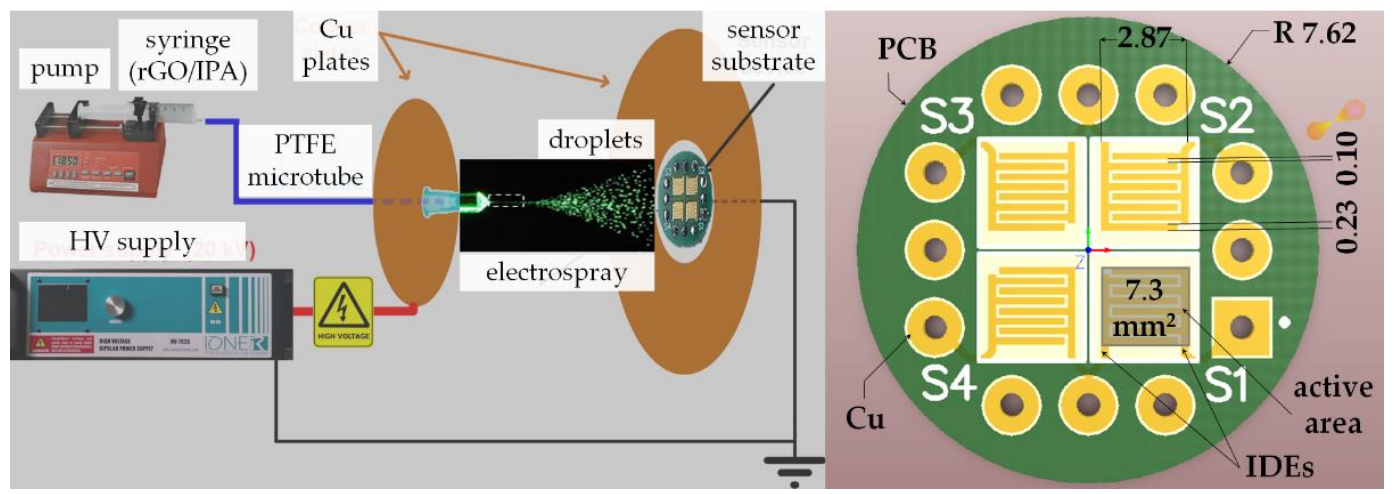

Figure 2. Left: Sketch of electrospray setup. Right: Draw of sensor substrate (dimensions in mm). 
Suspensions are prepared by pouring the rGO powder in a liquid and dispersing the rGO flakes in the solvent through ultrasonic agitation. It was necessary to optimize the solvent, the concentration of rGO and the ultrasonication time to ensure a high degree of dispersion of the rGO flakes in the suspension. Also, the dispersion must be stable to prevent logging of the capillary tube or the needle during sensor prepration. We do not use either surfactants or dispersants so as not to alter the gas sensing performance of the rGO. Finally, highly volative solvents are preferred, since they rapidly and fully evaporate from the droplets, and only the rGO flakes reach the substrate. After testing different solvents (e.g., deionized water, ethanol, isopropanol, acetone and ethylene glycol), we chose isopropanol (IPA) as the most suitable solvent for dispersing and electrospraying the rGO, and set the concentration of rGO in the suspension to $0.1 \mathrm{mg} / \mathrm{mL}$. An optimal rGO dispersion was attained after one hour sonication, and the dispersion remained stable (i.e., agglomeration of rGO flakes were not observed by the naked eye either in the syringe or in the capillary tube) for nearly half an hour.

\subsection{Sensor Characterization}

We characterized the sensing performance of the sensors based on electrosprayed rGO towards air pollutants like $\mathrm{NO}_{2}, \mathrm{O}_{3}$ and $\mathrm{CO}$. We used calibration cylinders of gas mixtures of $\mathrm{NO}_{2}$ and $\mathrm{CO}$ in dry air, and mixtures of $\mathrm{O}_{3}$ in dry air were generated by using an ozone generator based on a UV lamp (UVP SOG-1, Thermo Fisher Scientific Inc., USA) and an air cylinder. Figure 3 shows the facility used for sensor measurements with mixtures ozone-air.

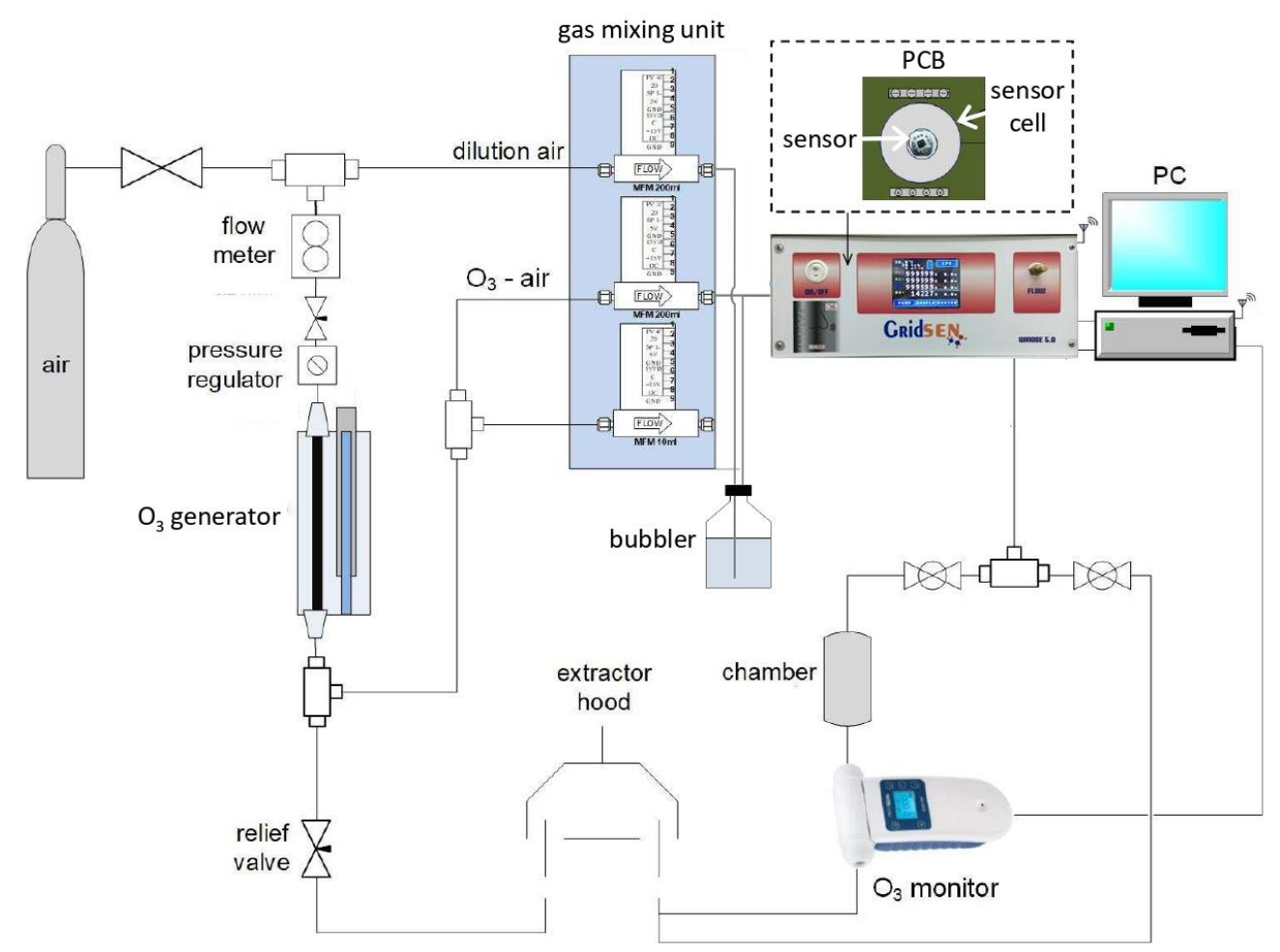

Figure 3. Layout of the facility used to characterize sensor detection performance towards ozone.

In the gas mixing unit (GMU-06, Ray Ingeniería Electrónica SL, Spain), the mixture O3-air from the ozone generator is diluted with dry air from the cylinder. Optionally, water is added to the gas by flowing the gas stream throuhg a bubbler and, then, the gas mixture enters the sensor cell. The gas flowrate is $0.2 \mathrm{~L} / \mathrm{min}$ and the concentration of $\mathrm{O}_{3}$ in the gas is measured downstream of the sensor cell by an ozone monitor including a semiconductor gas sensor (S500 and OZL, Aeroqual Ltd., New Zealand). The sensor cell has a free volume of $0.58 \mathrm{~cm}^{3}$ and temperarure and humidity sensors are placed on its top wall to continuously monitor the conditions inside the cell. The facility is fully automated and controlled by means of a program based on the LabView software. 


\section{Results}

\subsection{Electrospray Regime}

Figure 4 shows images of the liquid that comes out of the nozzle during electrospray of the rGO dispersion prepared as described in Section 2.2. The images were obtained by setting the distance between the needle and the substrate and the pump feedrate and increasing the applied voltage.

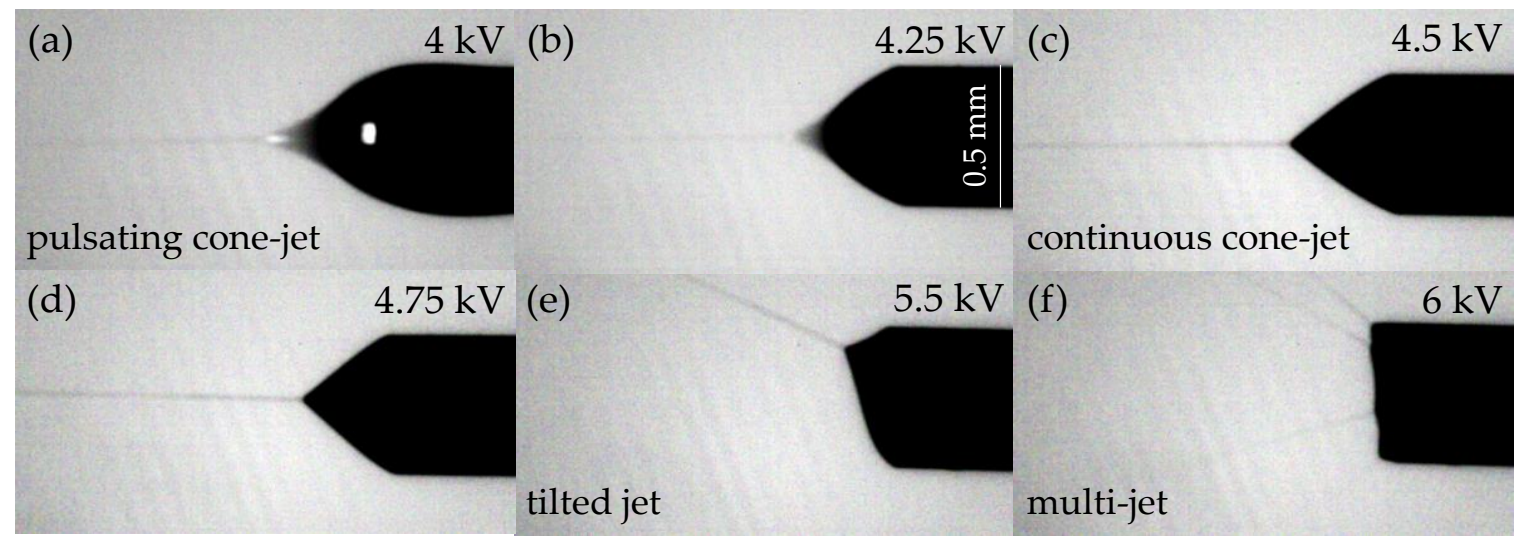

Figure 4. Camera pictures of the electrospray of a dispersion of $\mathrm{rGO}$ in isopropanol $(0.1 \mathrm{mg} / \mathrm{mL})$ with increasing applied voltage (needle-substrate distance: $15 \mathrm{~mm}$, flowrate: $5 \mu \mathrm{L} / \mathrm{min}$ ).

The different electrohydrodynamic jetting modes observed in Figure 4 have been extensively investigated [47-50]. In general, the liquid meniscus narrows and elongates under the action of the surface tension and the electric field and at a critical voltage a (Taylor) cone is formed. With further increasing of the electric field, the cone becomes unstable and a very thin jet (small and thin compared with the capillary diameter) is emitted from the cone apex. A pulsating cone-jet mode appears which pulsation frequency decreases with the increasing voltage and at the same time the concavely shape cone observed in the pulsation mode (a) changes to a nearly straight cone in the continuous conejet mode (c). A complex transition into a stable regime exists between pulsating and continuous cone-jet regime. Also a complex jetting behavior, like tilted jets (e) and multi-jets (f), is shown at higher electric field strenghts.

\subsection{Deposition Pattern}

We performed electrospray deposition tests varying the distance between the needle and the substrate $(6-30 \mathrm{~mm})$. After setting the needle-substrate distance, the flowrate and the voltage are adjusted until the cone-jet mode appeared and no liquid deposits on the substrate. Then, electrospray deposition is conducted for different values of the applied voltage and deposition time (5-20 min). After the tests, the rGO deposits formed onto the substrate are observed with an optical microscope (EM7-5TR, Meiji Tech, Japan) and pictures are taken by a digital camera connected to the microscope.

Figure 5 displays images of the rGO deposits found on the substrates when the electrospray operates in stable cone-jet mode. Then, the rGO forms circular spots on the substrate and the diameter of the spot decreases with the decreasing distance between the needle and the substrate. For distances larger than $15 \mathrm{~mm}$ the needle was centered in the circular substrate, whereas for distances less than $15 \mathrm{~mm}$ the needle was centered in the square IDEs. Figure $5 \mathrm{c}, \mathrm{d}$ correspond to the tests in which the needle-substrate distance was set to $15 \mathrm{~mm}$ and the needle pointed to either the center of the substrate or the center of the IDEs, respectively. It is observed that the rGO is fairly homogeneously distributed over the area of the deposits, particularly for the small spots in Figure 5e,f which area is comparable to the active area of the sensor. 

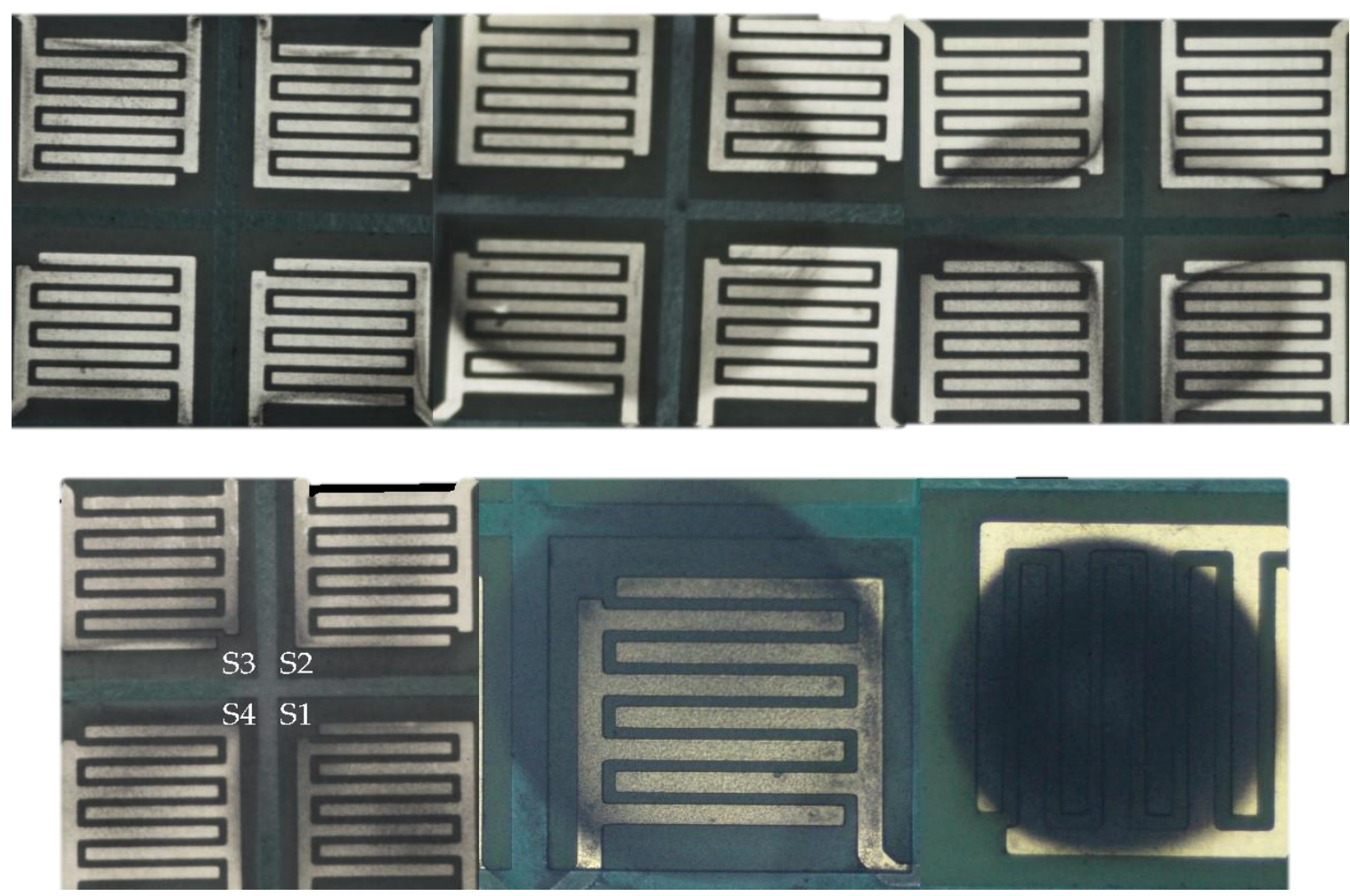

Figure 5. Camera pictures of rGO deposits obtained by electrospray of a dispersion of rGO in isopropanol $(0.1 \mathrm{mg} / \mathrm{mL})$. Needle-susbtrate distance, flowrate, voltage, and deposition time: (a) 30 $\mathrm{mm}, 8 \mu \mathrm{L} / \mathrm{min}, 5.5 \mathrm{kV}, 15 \mathrm{~min}$; (b) $25 \mathrm{~mm}, 6 \mu \mathrm{L} / \mathrm{min}, 5 \mathrm{kV}, 20 \mathrm{~min}$; (c) $15 \mathrm{~mm}, 4.25 \mathrm{kV}, 7 \mu \mathrm{L} / \mathrm{min}, 10$ min; (d) $15 \mathrm{~mm}, 5 \mu \mathrm{L} / \mathrm{min}, 4 \mathrm{kV}$, S1 \& S3: $10 \mathrm{~min}$, S2 \& S4: $5 \mathrm{~min}$; (e) $12 \mathrm{~mm}, 5 \mu \mathrm{L} / \mathrm{min}, 4.15 \mathrm{kV}, \mathrm{S} 1: 10$ min; (f) $7 \mathrm{~mm}, 3 \mu \mathrm{L} / \mathrm{min}, 2.7 \mathrm{kV}$, S1:15 min.

\subsection{Gas Detection}

We characterized the detection behaviour of the sensors based on electrosprayed rGO towards $\mathrm{NO}_{2}, \mathrm{O}_{3}$ and $\mathrm{CO}$. To illustrate that, we choose the sensors displayed in Figure 5d. Gas measurements were also conducted with the sensors in Figure $5 \mathrm{a}-\mathrm{c}$, but they showed a poorer performance: the resistance was out of the measurement range, the sensor response was very low and/or the signal to noise was unacceptable. No measuremenst have been performed yet with the sensors in Figure $5 \mathrm{e}, \mathrm{f}$. Sensors were exposed to mixtures of $\mathrm{NO}_{2}, \mathrm{O}_{3}$ or $\mathrm{CO}$ in air followed by clean air, at room temperature and variable relative humidity $(\mathrm{RH})$, between $5 \%$ and $60 \%$. The concentration of the target gas varied in the range of 0.05 to $0.3 \mathrm{ppm}\left(\mathrm{NO}_{2}, \mathrm{O}_{3}\right)$ and 0.5 to $5 \mathrm{ppm}(\mathrm{CO})$. The rGO behaved like a $p$-type semiconductor towards $\mathrm{NO}_{2}$ and $\mathrm{O}_{3}$ and was not able to detect $\mathrm{CO}$ in levels of up to $5 \mathrm{ppm}$.

Figures 6 and 7 show the dynamic resistance and the response of the sensors in Figure $5 \mathrm{~d}$ during the tests with mixtures of $\mathrm{NO}_{2}$-air and $\mathrm{O}_{3}$-air, respectively. The sensor response is defined as

$$
\operatorname{Res}(\%)=\frac{\left|R_{g}-R_{a}\right|}{R_{a}} \cdot 100
$$

where $R_{g}$ and $R_{a}$ stand for the resistance of the sensor exposed to the target gas, at the end of the detection phase, and the resistance of the sensor exposed to clean air, at the end of the recovery phase; respectively. As it can be observed, the sensors are more sensitive to $\mathrm{O}_{3}$ than $\mathrm{NO}_{2}$, and the response to bot gases increases with the increasing air humidity. At $20 \% \mathrm{RH}$ the sensor response to $0.05 \mathrm{ppm}$ $\mathrm{O}_{3}$ exceeds $1 \%$, whereas that response level is reached only at $0.2 \mathrm{ppm} \mathrm{NO}$. 

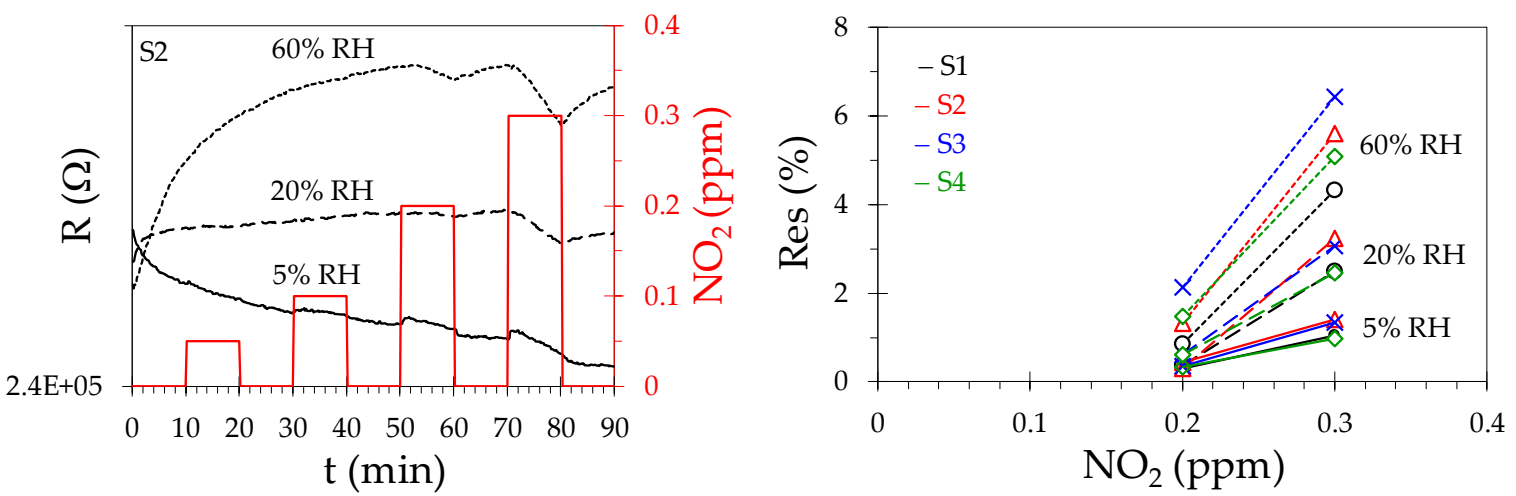

Figure 6. Dynamic resistance (left) and response (right) of sensors based on electrosprayed rGO under exposure to mixtures $\mathrm{NO}_{2}$-air with different $\mathrm{NO}_{2}$ and relative humidity level.
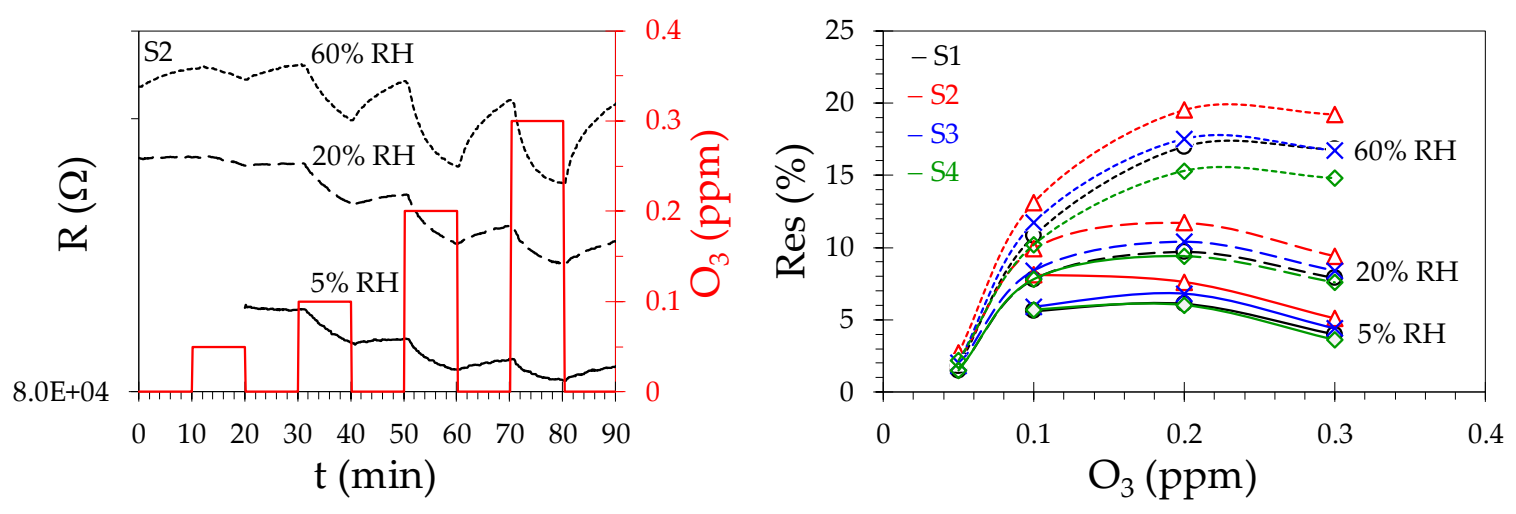

Figure 7. Dynamic resistance (left) and response (right) of sensors based on electrosprayed rGO under exposure to mixtures $\mathrm{O}_{3}$-air with different $\mathrm{O}_{3}$ and relative humidity level.

The sensor recovery time decreases with the increasing content of water in the gas. At $60 \% \mathrm{RH}$ the sensor resistance approaches the reference value $R_{a}$ after $10 \mathrm{~min}$ exposure to clean air. We attempted then to activate gas desorption from the rGO layer by irradiation with UV light. For that purpose, we installed a UV-LED light source (OCU-1400 UB355, $\lambda \sim 355 \mathrm{~nm}$, Osa Opto Light GmbH, Germany) centered on the upper wall of the sensor cell, at a distance of approximately $1 \mathrm{~cm}$ from the sensor surface. As an example, Figure 8 shows the results obtained when the sensors were exposed to clean air, after exposure to $0.1 \mathrm{ppm} \mathrm{O}_{3}$ in air with $20 \% \mathrm{RH}$. The sensors returned to the baseline resistance after 4 min of irradiation with UV light.
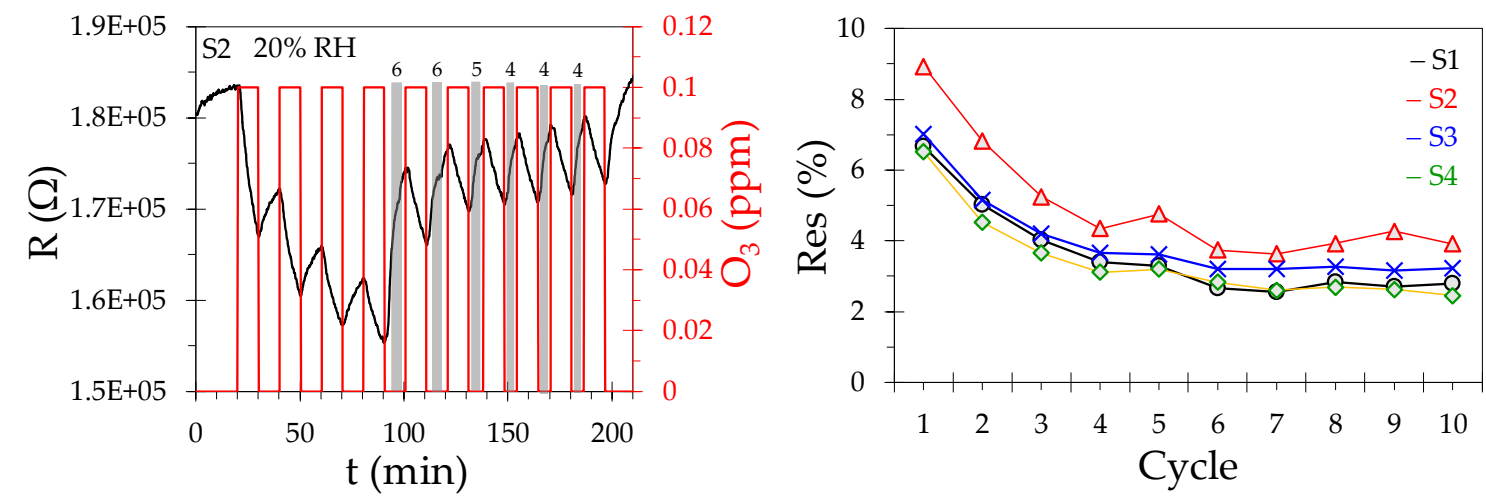

Figure 8. Dynamic resistance (left) and response (right) of sensors based on electrosprayed rGO under exposure to a mixture $\mathrm{O}_{3}$-air $(0.1 \mathrm{ppm} \mathrm{O}, 20 \% \mathrm{RH})$. After $90 \mathrm{~min}$ (cycle 4), sensors are irradiated with UV light for gas desorption during $6 \mathrm{~min}$ (cycles 4 \& 5), $5 \mathrm{~min}$ (cycle 6) and 4 min (cycles 7, 8 \& 9). 


\section{Discussion}

In this this work, we prove the feasibility of electrospray for the preparation of graphene films for gas sensing applications. We have been able to produce rather uniform graphene films over a wide range of areas $\left(7-100 \mathrm{~mm}^{2}\right)$ by electrospray of a rGO dispersion, operating the electrospray in contiuous cone-jet mode and varying the distance between the needle and the substrate. Nonetheless, the deposition pattern of graphene is strongly sensitive to the value of the applied voltage and small deviations from the ideal voltage (i.e., stable cone-jet mode) leads to highly inhomogeneous deposits that in some cases exhibited well-defined and reproducible patterns (e.g., circular or ellipsoidal rings). In the future, effort will be devoted to the preparation of homogeneous graphene layers for miniaturized sensors of active area below $1 \mathrm{~mm}^{2}$, which can only be attained by using nozzles of diameters $\leq 0.1 \mathrm{~mm}$ and nozzle-substrate distances $\leq 1 \mathrm{~mm}$.

The rGO used in this work shows good sensitivity to oxidizing gases like $\mathrm{NO}_{2}$ and $\mathrm{O}_{3}$, but is insensitive to a reducing gas such as CO. Sub-ppm levels of $\mathrm{NO}_{2}(0.2 \mathrm{ppm})$ and $\mathrm{O}_{3}(0.05 \mathrm{ppm})$ in air have been detected by sensors based on rGO films with average surface load of a few $\mu \mathrm{g} / \mathrm{mm}^{2}$. Further work will focus on the dependence of the sensor sensitivity on the rGO load and on the effect of the wavelength and intensity of the UV light on the sensor recovery time.

Author Contributions: Conceptualization and methodology, E.H.; validation, M.J.M. and S.M.; formal analysis, E.H. and M.J.M.; resources, S.E., J.L. and A.N.; writing - original draft preparation, E.H.; writing-review and editing, S.M. and M.J.M. All authors have read and agreed to the published version of the manuscript.

Funding: This research was funded by Program Interreg-Sudoe of the European Union (EU) under Grant Agreement SEO2/P1/E569-Project NanoSen-AQM (www.nanosenaqm.eu).

Conflicts of Interest: The authors declare no conflict of interest.

\section{References}

1. Briand, D.; Courbat, J. Micromachined semiconductor gas sensors. In Semiconductor Gas Sensors, 2nd ed.; Jaaniso, R., Tan, O.K., Eds.; Elsevier: Amsterdam, The Netherlands, 2019; pp. 413-465.

2. Hunter, G.W.; Akbar, S.; Bhansali, S.; Daniele, M.; Erb, P.D.; Johnson, K.; Liu, Ch.-Ch.; Miller, D.; Oralkan, O.; Hesketh, P.J.; Manickam, P.; et al. Editor's Choice-Critical Review - A critical review on solid state gas sensors. J. Electrochem. Soc. 2020, 167, 037570.

3. Joshi, N.; Hayasaka, T.; Liu, Y.; Liu, H.; Oliveira, O.N.; Lin, L. A review on chemiresistive room temperature gas sensors based on metal oxide nanostructures, graphene and 2D transition metal dichalcogenides. Microchim. Acta 2018, 185, 213, doi:10.1007/s00604-018-2750-5.

4. Zhang, J.; Liu, X.; Neri, G.; Pinna, N. Nanostructured Materials for Room-Temperature Gas Sensors. Adv. Mater. 2016, 28, 795-831, doi:10.1002/adma.201503825.

5. Demon, S.Z.N.; Kamisan, A.I.; Abdullah, N.; Noor, S.A.M.; Khim, O.K.; Kasim, N.A.M.; Yahya, M.Z.A.; Manaf, N.A.A.; Azmi, A.F.M.; Halim, N.A. Graphene-based Materials in Gas Sensor Applications: A Review. Sensors Mater. 2020, 32, 759, doi:10.18494/sam.2020.2492.

6. Tian, W.; Liu, X.; Yu, W. Research Progress of Gas Sensor Based on Graphene and Its Derivatives: A Review. Appl. Sci. 2018, 8, 1118, doi:10.3390/app8071118.

7. Singh, E.; Meyyappan, M.; Nalwa, H.S. Flexible Graphene-Based Wearable Gas and Chemical Sensors. ACS Appl. Mater. Interfaces 2017, 9, 34544-34586, doi:10.1021/acsami.7b07063.

8. Wang, T.; Huang, D.; Yang, Z.; Xu, S.; He, G.; Li, X.; Hu, N.; Yin, G.; He, D.; Zhang, L. A Review on Graphene-Based Gas/Vapor Sensors with Unique Properties and Potential Applications. Nano-Micro Lett. 2016, 8, 95-119, doi:10.1007/s40820-015-0073-1.

9. Varghese, S.S.; Lonkar, S.P.; Singh, K.; Swaminathan, S.; Abdala, A. Recent advances in graphene based gas sensors. Sensors Actuators B Chem. 2015, 218, 160-183, doi:10.1016/j.snb.2015.04.062.

10. Yuan, W.; Shi, G. Graphene-based gas sensors. J. Mater. Chem. A 2013, 1, 10078-10091, doi:10.1039/c3ta11774j.

11. Tarcan, R.; Todor-Boer, O.; Petrovai, I.; Leordean, C.; Astilean, S.; Botiz, I. Reduced graphene oxide today. J. Mater. Chem. C 2020, 8, 1198-1224, doi:10.1039/c9tc04916a. 
12. Sharma, N.; Vyas, R., Sharma, V.; Rahman, H.; Sharma, S.K.; Sachdev, K. A comparative study on gassensing behavior of reduced graphene oxide (rGO) synthesized by chemical and environment-friendly free method. Appl. Nanosci. 2020, 10, 517-528.

13. Lee, K.; Yoo, Y.K.; Chae, M.-S.; Hwang, K.S.; Lee, J.; Kim, H.; Hur, D.; Lee, J.H. Highly selective reduced graphene oxide (rGO) sensor based on a peptide aptamer receptor for detecting explosives. Sci. Rep. 2019, 9, 1-9, doi:10.1038/s41598-019-45936-z.

14. Drewniak, S.; Muzyka, R.; Stolarczyk, A.; Pustelny, T.; Kotyczka-Morańska, M.; Setkiewicz, M. Studies of Reduced Graphene Oxide and Graphite Oxide in the Aspect of Their Possible Application in Gas Sensors. Sensors 2016, 16, 103, doi:10.3390/s16010103.

15. Abdolhosseinzadeh, S.; Asgharzadeh, H.; Kim, H.S. Fast and fully-scalable synthesis of reduced graphene oxide. Sci. Rep. 2015, 5, 10160, doi:10.1038/srep10160.

16. Lu, G.; Ocola, L.E.; Chen, J. Reduced graphene oxide for room-temperature gas sensors. Nanotechnology 2009, 20, 445502, doi:10.1088/0957-4484/20/44/445502.

17. Kumar, R.; Liu, X.; Zhang, J.; Kumar, M. Room-Temperature Gas Sensors Under Photoactivation: From Metal Oxides to 2D Materials. Nano-Micro Lett. 2020, 12, 1-37, doi:10.1007/s40820-020-00503-4.

18. Li, W.; Guo, J.; Cai, L.; Qi, W.; Sun, Y.; Xu, J.-L.; Sun, M.; Zhu, H.; Xiang, L.; Xie, D.; et al. UV light irradiation enhanced gas sensor selectivity of $\mathrm{NO} 2$ and $\mathrm{SO} 2$ using rGO functionalized with hollow $\mathrm{SnO} 2$ nanofibers. Sens. Actuators B Chem. 2019, 290, 443-452, doi:10.1016/j.snb.2019.03.133.

19. Yan, X.; Wu, Y.; Li, R.; Shi, C.; Moro, R.; Ma, Y.; Ma, L. High-Performance UV-Assisted NO2 Sensor Based on Chemical Vapor Deposition Graphene at Room Temperature. ACS Omega 2019, 4, 14179-14187, doi:10.1021/acsomega.9b00935.

20. Espid, E.; Taghipour, F. UV-LED Photo-activated Chemical Gas Sensors: A Review. Crit. Rev. Solid State Mater. Sci. 2016, 42, 416-432, doi:10.1080/10408436.2016.1226161.

21. Dai, J.; Ogbeide, O.; Macadam, N.; Sun, Q.; Yu, W.; Li, Y.; Su, B.-L.; Hasan, T.; Huang, X.; Huang, W. Printed gas sensors. Chem. Soc. Rev. 2020, 49, 1756-1789, doi:10.1039/c9cs00459a.

22. Khan, S.; Lorenzelli, L.; Dahiya, R.S. Technologies for Printing Sensors and Electronics Over Large Flexible Substrates: A Review. IEEE Sens. J. 2014, 15, 3164-3185, doi:10.1109/jsen.2014.2375203.

23. Ru, C.; Luo, J.; Xie, S.; Sun, Y. A review of non-contact micro- and nano-printing technologies. J. Micromech. Microeng. 2014, 24, 053001, doi:10.1088/0960-1317/24/5/053001.

24. Pandhi, T.; Chandnani, A.; Subbaraman, H.; Estrada, D. A Review of Inkjet Printed Graphene and Carbon Nanotubes Based Gas Sensors. Sensors 2020, 20, 5642, doi:10.3390/s20195642.

25. Travan, C.; Bergmann, A. NO2 and NH3 Sensing Characteristics of Inkjet Printing Graphene Gas Sensors. Sensors 2019, 19, 3379, doi:10.3390/s19153379.

26. Wu, T.-C.; De Luca, A.; Zhong, Q.; Zhu, X.; Ogbeide, O.; Um, D.-S.; Hu, G.; Albrow-Owen, T.; Udrea, F.; Hasan, T. Inkjet-printed CMOS-integrated graphene-metal oxide sensors for breath analysis. npj 2D Mater. Appl. 2019, 3, 42 10, doi:10.1038/s41699-019-0125-3.

27. Zhang, H.; Xie, A.; Shen, Y.; Qiu, L.; Tian, X. Layer-by-layer inkjet printing of fabricating reduced graphenepolyoxometalate composite film for chemical sensors. Phys. Chem. Chem. Phys. 2012, 14, 12757-12763, doi:10.1039/c2cp41561e.

28. Le, T.; Lakafosis, V.; Lin, Z.; Wong, C.P.; Tentzeris, M.M. Inkjet-printed graphene-based wireless gas sensor modules. In Proceedings of the 2012 IEEE 62nd Electronic Components and Technology Conference, San Diego, CA, USA, 29 May-1 June 2012; pp. 1003-1008.

29. Dua, V.; Surwade, S.P.; Ammu, S.; Agnihotra, S.R.; Jain, S., Roberts, K.E.; Park, S.; Ruoff, R.S.; Manohar, S.K. All-organic vapor sensor using inkjet-printed reduced graphene oxide. Angew. Chem. Int. Ed. 2010, 49, $1-5$.

30. Brown, N.A.; Gladstone, J.N.; Chiarot, P.R. Brown, N. A.; Gladstone, J. N.; Chiarot, P. R. Materials Printing using Electrospray. In Proceedings of the 2014 ASME International Mechanical Engineering Congress and Exposition, IMECE2014, Montreal, QC, Canada, 14-20 November 2014; p.38336.

31. Jaworek, A., Sobezyk, A.T. Electrospray route to nanotechnology. An overview. J. Electrostat. 2008, 68, 197219.

32. Jaworek, A. Electrospray droplet sources for thin film deposition. J. Mater. Sci. 2006, 42, 266-297, doi:10.1007/s10853-006-0842-9.

33. Deng, W.; Waits, C.M.; Gomez, A. Digital electrospray for controlled deposition. Rev. Sci. Instrum. 2010, 81, 35114, doi:10.1063/1.3340907. 
34. Fan, X.; Xu, Y.; Ma, C.; He, W. In-situ growth of Co3O4 nanoparticles based on electrospray for an acetone gas sensor. J. Alloy. Compd. 2021, 854, 157234, doi:10.1016/j.jallcom.2020.157234.

35. Li, W.; Lin, J.; Wang, X.; Jiang, J.; Guo, S.; Zheng, G. Electrospray Deposition of ZnO Thin Films and Its Application to Gas Sensors. Micromachines 2018, 9, 66, doi:10.3390/mi9020066.

36. Tang, J.; Gomez, A. Controlled mesoporous film formation from the deposition of electrosprayed nanoparticles. Aerosol Sci. Technol. 2017, 51, 755-765, doi:10.1080/02786826.2017.1303573.

37. Jasek, K.; Pasternak, M.; Grabka, M.; Neffe, S.; Zasada, D. Deposition of Polymer Sensor Films on SAW Surface by Electrospraying Technology. Arch. Acoust. 2017, 42, 507-513, doi:10.1515/aoa-2017-0054.

38. Zheng, G.; Zhu, P.; Sun, L.; Jiang, J.; Liu, J.; Wang, X.; Li, W. Thin film zinc oxide gas sensor fabricated using near-field electrospray. AIP Adv. 2016, 6, 125306, doi:10.1063/1.4971273.

39. Gürbüz, M.; Günkaya, G.; Doğan, A. Electrospray deposition of SnO2films from precursor solution. Surf. Eng. 2015, 32, 725-732, doi:10.1080/02670844.2015.1108048.

40. Varea, A.; Monereo, O.; Xuriguera, E.; Prades, J.D.; Cirera, A. Electrospray as a suitable technique for manufacturing carbon-based devices. J. Phys. D Appl. Phys. 2017, 50, 315301, doi:10.1088/1361-6463/aa798b.

41. Taylor, A.P.; Velasquez-Garcia, L.F. Electrospray-printed nanostructured graphene oxide gas sensors. Nanotechnology 2015, 26, 505301, doi:10.1088/0957-4484/26/50/505301.

42. Wall, M. The Raman Spectroscopy of Graphene and the Determination of Layer Thickness. Available online: http://tools.thermofisher.com/content/sfs/brochures/AN52252_E\%201111\%20LayerThkns_H_1.pdf (accessed on 22 October 2020).

43. Hidayah, N.M.S.; Liu, W.-W.; Lai, C.-W.; Noriman, N.Z.; Khe, C.-S.; Hashim, U.; Lee, H.C. Comparison on graphite, graphene oxide and reduced graphene oxide: Synthesis and characterization. AIP Conf. Proc. 2017, 1892, 150002, doi:10.1063/1.5005764.

44. Strankowski, M.; Wlodarczyk, D.; Piszczyk, Łukasz; Strankowska, J. Polyurethane Nanocomposites Containing Reduced Graphene Oxide, FTIR, Raman, and XRD Studies. J. Spectrosc. 2016, 2016, 1-6, doi:10.1155/2016/7520741.

45. Saleem, H.; Haneef, M.; Abbasi, H.Y. Synthesis route of reduced graphene oxide via thermal reduction of chemically exfoliated graphene oxide. Mater. Chem. Phys. 2018, 204, 1-7, doi:10.1016/j.matchemphys.2017.10.020.

46. Stobinski, L.; Lesiak, B.; Malolepszy, A.; Mazurkiewicz, M.; Mierzwa, B.; Zemek, J.; Jiricek, P.; Bieloshapka, I. Graphene oxide and reduced graphene oxide studied by the XRD, TEM and electron spectroscopy methods. J. Electron Spectrosc. Relat. Phenom. 2014, 195, 145-154, doi:10.1016/j.elspec.2014.07.003.

47. Rosell-Llompart, J.; Grifoll, J.; Loscertales, I.G. Electrosprays in the cone-jet mode: From Taylor cone formation to spray development. J. Aerosol Sci. 2018, 125, 2-31, doi:10.1016/j.jaerosci.2018.04.008.

48. Zhou, J.; Gao, D.; Yao, D.; Leist, S.K.; Fei, Y. Mechanisms and modeling of electrohydrodynamic phenomena. Int. J. Bioprinting 2018, 5, 166, doi:10.18063/ijb.v5i1.166.

49. Lee, A.; Jin, H.; Dang, H.-W.; Choi, K.H.; Ahn, K.H. Optimization of Experimental Parameters To Determine the Jetting Regimes in Electrohydrodynamic Printing. Langmuir 2013, 29, 13630-13639, doi:10.1021/la403111m.

50. Gomez, A.; Deng, W. Fundamentals of Cone-Jet Electrospray. In Aerosol Measurement; Wiley: Hoboken, NJ, USA, 2011; pp. 435-448.

Publisher's Note: MDPI stays neutral with regard to jurisdictional claims in published maps and institutional affiliations.

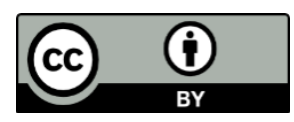

(C) 2020 by the authors. Submitted for possible open access publication under the terms and conditions of the Creative Commons Attribution (CC BY) license (http://creativecommons.org/licenses/by/4.0/). 